\title{
Figuras de uma história e de uma geografia incessantemente reinventadas na ficção de António Lobo Antunes
}

\author{
Angela Beatriz de Carvalho Faria \\ Universidade Federal do Rio de Janeiro \\ Qual ser amado não envolve paisagens, \\ continentes e populações mais ou menos \\ conhecidos, mais ou menos imaginários?
}

DELEUZE, Gilles. Crítica e clínica.

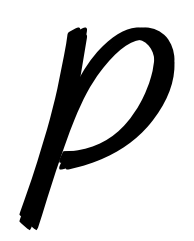

ensar em um determinado trauma histórico como uma questão ética e política não terá sido a intenção de António Lobo Antunes, ao escrever o romance Comissão das Lágrimas, publicado em 2011, capaz de justapor ou superpor o imaginário e o real, duas faces que não param de intercambiar-se, espelho móvel, na ótica delleuziana? Ou será que a possível existência de uma "Comissão" denominada "das Lágrimas" perde a sua qualidade de evento histórico específico e começa a funcionar como uma metáfora para outras histórias e memórias? Pensamos, a princípio, que as hipóteses não são excludentes. Tais conjecturas apóiam-se, inclusive, na entrevista concedida pelo autor à televisão portuguesa (SIC), por ocasião da publicação do romance. ${ }^{1}$ Qual

\footnotetext{
${ }^{1}$ Lobo Antunes e a "Comissão das Lágrimas" - SIC... - SAPO Vídeos: vídeos.sapo.pt/6iRhyOZAPhnUCNDzOV4v
} 
teria sido a intenção de Lobo Antunes, ao revisitar figuras da História e da Geografia angolanas? Qual teria sido o objetivo de Lobo Antunes, ao reencenar resíduos ou fragmentos de um trauma original e explorá-lo na representação literária? Desejaria Lobo Antunes impedir o esquecimento da violação dos direitos humanos e denunciar uma ética agonística, assinalada por uma história de extermínio em massa, ocorrida em Angola, após a independência do país?

$\mathrm{Ou}$, ao perder a sua ancoragem na referencialidade do real, o passado histórico revisitado no presente, a ficção antuniana revelaria uma estratégia contemporânea de desrealização narcísica, ao sucumbir a um poder mágico de simulação e de projeção de imagens, retidas na memória? Pensamos ser impossível dar uma resposta única, uma vez que as estratégias de rememoração de um trauma podem ser, elas mesmas, transitórias e incompletas - marcas, aliás, contundentes da enunciação discursiva e da configuração temática inerentes às obras do autor, metaforizadas pelas expressões "as flores do inferno" e "jardins suspensos", da autoria de Maria Alzira Seixo, ${ }^{2}$ como veremos mais adiante. $\mathrm{O}$ próprio Lobo Antunes, ao ser questionado pelo jornalista que o entrevistava sobre a relação entre realidade e ficção, fez as seguintes afirmações: "Resta saber se a realidade existe ou não"; "O que nos interessa é a nossa vida interior", "o regresso à antropofagia da fome continuada", "o regresso à noite escura de nós mesmos". E, continua ele: "Comissão das Lágrimas é um livro simbólico que focaliza os sentimentos mais profundos do ser humano" e centra-se "no que se passa na cabeça da rapariga que parece fazer um ajuste de contas com ela mesma". Além disso, segundo o próprio autor, o que sobressai, no romance, é "a ausência de importância da morte".

2 SEIXO, 2010. 
Sobre isso, Miguel Real, em um ensaio crítico, publicado no Jornal de Letras, Artes e Ideias de Lisboa, afirma:

Assim, ler Comissão das Lágrimas é como se cada leitor reconstruísse dentro de si um novo "Guernica": corpos fragmentados, mentes estilhaçadas, sentimentos benéficos amarrotados, os "cães negros" do inconsciente maligno emergidos, soltos, situações sociais aterrorizantes - o terror em cada página, um inferno em forma de arte."

À qual situação, aludida no romance de Lobo Antunes, estaria referindo-se o crítico, acima citado, e que possibilitou a ele estabelecer uma comparação com o quadro "Guernica", de Pablo Picasso, que representa a destruição da cidade pela aviação alemã (1937), por ocasião da guerra civil espanhola? Vejamos.

Fraccionismo foi o nome dado a um movimento político angolano, liderado por Nito Alves, ex-dirigente do MPLA, no poder desde a independência do país. Este movimento articulou-se como dissidência no seio do MPLA, após a independência de Angola, em oposição ao Presidente Agostinho Neto e lançou em Luanda uma tentativa de Golpe de Estado a 27 de maio de 1977.

O golpe fracassou devido ao apoio das FARC (forças cubanas estacionadas em Angola), e após um breve período de acalmia em que tudo parecia estar solucionado, deu-se um atentado à vida do Presidente Agostinho Neto, que levou a um período de dois anos de perseguição sangrenta dos (reais e alegados) seguidores e simpatizantes de Nito Alves, culminando em milhares de mortos.

Na ocasião, foi criado um Tribunal Militar Especial, vulgo Comissão Revolucionária, e que ficou conhecido como Comissão das Lágrimas. Imensas pessoas foram submetidas a prisões arbitrárias, torturas, condenações sem julgamento

${ }^{3} \mathrm{JL}$, edição 1069, de 21 set. 2011. 
ou execuções sumárias. Estima-se o número de mortos entre 15.000 e 80.000 .

Não se sabe a data exata em que Nito Alves, que lutava pela adoção da ideologia marxista-leninista pelo MPLA, foi preso, mas sabe-se que foi fuzilado e que se fez desaparecer o seu corpo, afundando-o no mar amarrado a pedras.

Virinha, dirigente do destacamento feminino das FAPLA (Forças Armadas Populares de Libertação de Angola) comanda o assalto à cadeia de São Paulo, é feita prisioneira, torturada e morta, na sequência dos terríveis acontecimentos ocorridos. ${ }^{4}$

Em Comissão das Lágrimas, de Lobo Antunes, "um inferno em forma de arte", tal contexto histórico surge insinuado e transcrito, através de resíduos e fragmentos obsedantes no espaço textual: a barbárie cometida pela Comissão das Lágrimas, em Angola, no período pós-independência de Portugal; a dizimação dos dissidentes do MPLA; a tortura e morte de Virinha (personagem real sem nome no romance) e seu canto incessante que ninguém conseguia calar, uma vez que "a rapariga não cantava com a boca cantava com o corpo todo" ${ }^{.}$Há, portanto, um canto fantasmático a vencer a morte, incorruptível e inalterado, ameaçador, e, infinitamente retido na memória do torturador. Canto capaz de provar que o poder do Estado é ilusório e de que há um "jardim suspenso" ("um improviso e uma fantasia"; "uma luminosidade e vibração humana") em

${ }^{4}$ Informações colhidas na Wikipédia, enciclopédia livre, em 03.10.2012. Convém acrescentar que o órgão responsável pelo ato de recolher depoimentos dos envolvidos no suposto Golpe de Estado, a DISA (Direção de Informação e Segurança de Angola), foi extinto por Agostinho Neto, em julho de 1977, em decorrência dos "excessos" que havia cometido.

${ }^{5}$ LOBO ANTUNES, 2011, p. 164 
meio às "flores do Inferno" ("aos sofrimentos em vida ligados à perspectiva da morte"). ${ }^{6}$

Ao narrar a História, o autor pensa a questão política de uma forma singular: resgata o momento da perda irreparável - o desaparecimento do modelo ideal de virtudes e de sentimentos humanitários; a ausência de piedade ética e de misericórdia cristã; a violência ilegal do Estado, capaz de simular a defesa de seus cidadãos; a violação dos direitos humanos e a rotina do terror. Uma vez instaurado um estado de exceção, seguem-se a tortura, os tratamentos ou castigos cruéis, inumanos ou degradantes; a detenção prolongada sem acusação; os desaparecimentos em conseqüência de seqüestros; as detenções clandestinas ou outras violações de direitos de vida, liberdade e segurança das pessoas.7 Lemos, no romance antuniano, fragmentos correlacionados a atos recorrentes de crueldade, capazes de superpor espaços e tempos diferenciados (Luanda, Quibala, Lisboa, entre outros; os anos de 1967, 1974/75, 1977 e 2007). Nesse relato poliédrico, uma das vozes, identificada com o comissário, principal membro da Comissão das Lágrimas, pronuncia-se:

e isto que conto afogado em silêncio apesar do gramofone do senhor Figueiredo e dos gritos na Cadeia de São Paulo, não somente na Cadeia de São Paulo, na Casa de Reclusão, na Fortaleza de São Miguel, nos baldios a seguir aos musseques, à beira das estradas /.../ cruzes de vidas extintas," "musseques, gente a correr, aqueles que uma traineira vai largando na baía, agarram-se à noite pela cabeça, os joelhos e a sombra abre os braços e leva-os.";

${ }^{6}$ SEIXO, 2010, p. 17-25.

7 PINHEIRO, 1991, p. 191-204.

${ }^{8}$ LOBO ANTUNES, 2011, p. 123.

${ }^{9}$ LOBO ANTUNES, 2011, p. 40. 
“emboscámos os portugueses, noites geladas do Leste, cabritos esventrados que os pássaros comiam, não conheci senão episódios deste gênero."; 10 "cessamos de existir na Comissão das Lágrimas e torturamos espectros, o sujeito à minha direita a vomitar os olhos"); ${ }^{11}$ "Luanda uma gaveta de facas sempre aberta" ${ }^{12}$

É interessante observar, na prosódia do texto de ficção, que privilegia a Estética da Crueldade, ${ }^{13}$ a presença de metáforas, analogias, paroxismos, interditos, eufemismos e simulacros aliada a uma "ética das imagens" que nos faz "ver o invisível", como nos ensina Nelson Brissac Peixoto. ${ }^{14}$ Assim, "ao tirar o passado da gaveta mais funda da memória"15 e ao constatar que "tudo se mastiga em Angola a começar pelas pessoas", 16 o personagem-torturador transmuta os "buracos abertos pelas balas" em "rosas que ardem sozinhas logo desde botões, pontinhos vermelhos a consumirem-se crescendo mas isso os búzios não contam"17 ou "e cada bala uma florinha vermelha a sacudir-lhe o corpo" ${ }^{18}$ Em Comissão das Lágrimas, há "gestos e imagens em suspensão, capazes de conter o tempo e que retêm emoções e sentimentos que não podem ser

${ }^{10}$ LOBO ANTUNES, 2011, p. 62.

${ }^{11}$ LOBO ANTUNES, 2011, p.155.

12 LOBO ANTUNES, 2011, p.85.

${ }^{13}$ A esse respeito, remeto à leitura da obra Estéticas da Crueldade, organizada por Ângela Maria Dias e Paula Glenadel. Rio de Janeiro: Atlântica Editora, 2004.

14 PEIXOTO, 1992, p. 301-320.

15 LOBO ANTUNES, 2011, p.168.

${ }^{16}$ LOBO ANTUNES, 2011, p.238.

${ }^{17}$ LOBO ANTUNES, 2011, p.113.

${ }_{18}$ LOBO ANTUNES, 2011, p.157. 
silenciados". ${ }^{19}$ Assim, o canto de Virinha reflete o seu caráter, os seus princípios de vida, a sua alma, os seus desejos e conflitos, o que faz com que esta imagem (a mulher aprisionada que continua a cantar sob tortura) se torne mais verdadeira. Virinha torna-se capaz de corporificar um "fantasma" da História, a que regressa exigindo um enterro apropriado e o devido respeito para que o processo de luto possa ter início. Aquela que, por qualquer razão, viveu uma história que não pode ser contada, cuja vida foi tragicamente interrompida, em decorrência de uma "má morte". Jo Labanyi, em "O reconhecimento dos fantasmas do passado: história, ética e representação", ${ }^{20}$ ao relacionar os fantasmas com os vencidos da história, com a dor e com a queixa, considera-os "a corporização de um tipo de luto impossível de realizar porque as condições de luto - uma "boa morte", um "corpo bem enterrado" - não se cumpriram". A ensaísta, inclusive, alude a Os espectros de Marx, da autoria de Derrida, para sublinhar que, "tal como existe um modo de produção de mercadoria, também existe um modo de produção por meio do luto" 21 e às reflexões de Walter Benjamin sobre as ruínas da História, espaço, por excelência, que os fantasmas costumam freqüentar. Dessa forma, continua ela, Benjamin "atribui ao historiador" (e, diríamos nós, ao ficcionista) "a função de resgatar do passado o potencial esquecido, cuja realização foi frustrada.". Virinha, portanto, a mulher torturada pela Comissão das Lágrimas, pertenceria ao paradigma dos "refugiados da História", "pessoas deslocadas, homens e mulheres sem país, lançados

${ }^{19}$ PEIXOTO, 1992, p. 308.

${ }^{20}$ LABANYI, 2003, p.59-68.

${ }^{21}$ DERRIDA, Jacques. Specters of Marx: the state of debt, the work of mourning, and the new international. Nova Iorque e Londres, Routledge, 1994, p.97 apud LANANYI, Jo.Op. cit. Ver nota 10. 
fora do tempo, os mortos vivos". ${ }^{22}$ Essa "figura de uma história e de uma geografia incessantemente reinventadas" ressurge, na ficção de Lobo Antunes, como uma imagem fantasmática, retida na memória da personagem representante da Comissão das Lágrimas, e capaz de assombrá-la incessantemente, como atesta um fragmento do romance analisado que denuncia $o$ processo de tortura:

a rapariga que não parava de cantar enquanto lhe batiam, erguiam-na com um gancho, deixavam-na cair, escutavam-se-lhe as gengivas contra o cimento e ela a cantar com as gengivas, uma bala no ventre e cantava, inclusive sem nariz e sem língua, e o nariz e a língua substituídos por coágulos vermelhos, continuava a cantar, julgaram calá-la com um revólver no coração e os arbustos do pátio tremiam, pergunto-me se em lugar dos arbustos eram as minhas mãos que não achavam repouso. ${ }^{23}$

Virinha, portanto, era detentora de um canto que venceria a "má morte" imputada a ela e tornar-se-ia um "fantasma" da História. Impossibilitada de contar a sua própria história, delegaria a outrem a redenção de um trauma, uma vez que "a cura para o trauma" consiste em "aprender a contar a história daquilo que é inarticulável". O seu aparecimento, na ficção antuniana, interrompe, pois, a narrativa dominante que a excluiria e, por isso, torna-se capaz de fraturar a coerência aparente de um relato oficial, baseado em simulacros. O comissário-torturador, ex-padre e negro, representante da opressão e do poder instituído, por sua vez, deseja, anos depois, já instalado em um apartamento de Lisboa, a jogar xadrez e a querer expiar a sua culpa, que "os

${ }^{22}$ MARCUS, Greil. The dustbin of history. Londres, Picador, 1997. p.17 apud LABANYI, Jo. Op. cit., p.62. Ver nota 10.

${ }^{23}$ ANTUNES, 2011, p.35. 
mestiços venham buscá-lo", que "a pistola ou a catanha ou a faca" o matassem, que "a rapariga cessasse de cantar e o deixasse em paz". E chega à conclusão de que "a única solução é apagar o passado". ${ }^{24}$ No último capítulo do romance, a filha, Cristina, ouve um "Adeus" e, ao chamar o pai (ou aquele que julgava ser seu pai), constata a ausência de resposta, "porque o sudário da água o não deixava escut[á-la]". ${ }^{25}$ A última imagem fixada no romance - o provável afogamento, nas águas do rio Tejo, do personagem que representava a opressão - instaura a dúvida: morte imputada por outrem ou suicídio? De qualquer maneira, inverte-se a significação simbólica da água - não mais fonte de vida ou meio de purificação, mas, sim, de desintegração ou de dissolução absoluta. E, além disso, pode-se afirmar, fazendo nossas as palavras de Nelson Brissac Peixoto, que "a cintilação da água do rio ilumina os percursos sórdidos na cidade e nas existências" ${ }^{26}$

Segundo o ensaísta citado, em "Ver o invisível: a ética das imagens", "esta exigência de se abrir ao que, na paisagem, não se evidencia, é que, por fim, para Lyotard, em L'Inhuman, ou "Desumano", é ética. Assim, a partir dessa reflexão crítica, poderíamos dizer que a ficção de Lobo Antunes, autorreferencial e autorreflexiva, motivada por conscientes atitudes ética e estética, atesta a presença de determinadas imagens, ao mesmo tempo que as rasura; insinua significações, propositalmente, ambíguas e lacunares; assume-se como "testemunha" (im)precisa de um determinado tempo e espaço; exige de si própria apresentar o inapresentável, dizer o indizível. Há, inclusive, imagens em trânsito - aquelas atribuídas a mais de uma personagem - que refletem o espelhamento ficcional, a presença de ecos, a

${ }^{24}$ ANTUNES, 2011, p. 326.

${ }^{25}$ ANTUNES, 2011, p. 326.

${ }^{26}$ AFONSO,2008, p. 357-360. 
problemática da dispersão e do desdobramento de identidades, a dificuldade ou incapacidade de se expressar emoções e sentimentos, "o regresso ao inconsciente e ao negrume da alma". ${ }^{27}$ Há, no romance selecionado, inúmeras imagens que referenciam as "flores do inferno", marcadas pela desorientação psíquica dos sujeitos, decorrente de traumas vivenciados. Entre elas, destacamse: o corpo - "esquartejado" pelo abuso sexual - de Alice/Simone (mãe de Cristina, ex-corista do estabelecimento do Sr.Figueiredo, trazida de barco de Lisboa para relacionar-se, sexualmente, com os colonos ricos) - que, uma vez grávido, é percebido por ela como "valado de perdizes a crescer-[lhe] no umbigo", ${ }^{28}$ a cena do seminário e a relação homossexual interdita e considerada pecaminosa (quem o violador?, quem o violentado?); a imagem de sujeitos despaisados, na geografia do exílio; as litanias litúrgicas que se confundem com enunciações de barbárie; os silêncios cristalizados e mais significativos do que as falas; e os objetos, metaforicamente, amputados, capazes de remeter ao "ser humano tolhido em miséria e frustração", 29 como evidenciamos em um dos fragmentos do romance antuniano: "e em lugar de palavras ofereci-lhe uma açucena, a mesma que lhe estendo agora, sem nenhum caule na mão." ${ }^{30}$

Entre as vozes superpostas, deslizantes e intermutáveis, presentes em Comissão das Lágrimas, destaca-se a de Cristina, internada para tratamento em um hospital psiquiátrico, que recupera, através de outras vozes inusitadas que a invadem, "insultam e dão ordens", ${ }^{31}$ memórias reais ou "inventadas",

${ }^{27}$ LOBO ANTUNES, 2011. Entrevista à SIC.

${ }^{28}$ ANTUNES, 2011, p. 23.

${ }^{29}$ SEIXO, Maria Alzira, 2010, p. 134.

${ }^{30}$ ANTUNES, 2011, p. 166.

${ }^{31}$ ANTUNES, 2011, p. 131. 
fragmentos do contexto histórico e da origem familiar. Ao ser diagnosticada com "demência progressiva" pelo médico, a personagem depara-se com "ondas de frases que a assaltavam e deixavam abandonando conchas de palavras no ângulo da memória, nem palavras sequer, imagens sem nexo". ${ }^{32}$ Antes, porém, tinha "o poder de evocar imagens in absentia; imagens de tudo aquilo que não é, mas poderia ter sido; imagens que fazem falar o que não tem palavra". ${ }^{33}$ Dessa forma, Cristina (criança, que saiu de África, aos cinco anos; agora, uma mulher adulta, de cerca de 49 anos, que mora em Lisboa) transfigura o real e imerge em seu imaginário, ouve as folhas das árvores que se aproximarão das folhas de papel a serem escritas: "de tempos a tempos um arrepio nas árvores e cada folha uma boca numa linguagem sem relação com as outras". ${ }^{34}$ A dispersão ou fragmentação identitária ${ }^{35}$ acometerá a personagem feminina que perderá contorno e consistência, mediante o apagamento da memória, ao perceber as "sombras das recordações que surgem, desaparecem "e que não consegue "deter":

- Quem sou?

Porque desde que as bocas das folhas e as vozes se calaram me interrogo e continuo, deixei de ser eu ou me tornei noutra coisa, sem substância nem contornos, água derramada que se move no soalho de acordo com o desnível das tábuas. ${ }^{36}$

32 ANTUNES, 2011, p. 280.

33 PEIXOTO, 1992, p. 315.

34 ANTUNES, 2011, p. 11.

35 ANTUNES, 2011, p. 67.

${ }^{36}$ ANTUNES, 2011, p. 167. 
Talvez não seja por acaso que a sensação de diluição da personagem (responsável pela maior parte da narração da história e da sua desescrita) em "água derramada que se move no soalho de acordo com o desnível das tábuas" seja sucedida pela extinção da Comissão das Lágrimas: "A Comissão das Lágrimas a desvanecer-se no fundo de areia, somos um país, não um lugar, já não há África". ${ }^{37}$ A desaparição de um órgão político, marcado pela violência e arbitrariedade, talvez seja capaz de instaurar a pólis - "espécie de comunidade (koinomia) feita com uma finalidade precisa: permitir a vida boa ou justa ou feliz, que só é possível para os que são livres ou independentes", ${ }^{38}$ o que nos remete às reflexões de Aristóteles, em Ética à Nicômano. ${ }^{39}$ Assim, a contingência e a crise dos valores morais e políticos inserem-se na modernidade e na ficção ética de Lobo Antunes.

Segundo Marilena Chauí, no ensaio, "Público, Privado, Despotismo", "por natureza os homens são seres livres e destinados à vida política porque somente eles têm o dom da palavra, o logos, que lhes permite distinguir entre o bem e o mal, o justo e o injusto e todos os valores". ${ }^{40}$ Talvez, por isso, a personagem Cristina, voz responsável pela invenção dos sujeitos que habitam o espaço romanesco, no último capítulo tenha obedecido a uma voz intrusa ( a do autor?), escutada anteriormente: "na ruína das feições, volta ao teu pai e à África, Cristina, multiplica as lanternas, multiplica as pistolas, matanos a todos depressa". ${ }^{41}$ Talvez, por isso, o pai, principal

\footnotetext{
${ }^{37}$ ANTUNES, 2011, p. 228.

${ }^{38}$ CHAUÍ, 1992, p. 357.

${ }^{39}$ NOVAES, 1992, p. 7-15.

${ }^{40}$ CHAUÍ, 1992, p. 357.

${ }^{41}$ ANTUNES, 2011, p. 274.
} 
representante da Comissão das Lágrimas, após deambular pelas ruas de Lisboa, perseguido, à distância, pelo olhar da filha, tenha ficado submerso nas águas do Tejo. Assim o romance, capaz de revisitar a dor e a violência na modernidade, chega ao fim, conciliando as duas hipóteses presentes no início desta comunicação: a articulação de uma denúncia política - a presença de uma ética agonística inerente à Comissão das Lágrimas e a singular representação estética, caracterizada pelo “assombrado vaivém das ondas que, pouco a pouco, levará os leitores ao encontro da treva fatal, indispensável ao renascimento e à renovação do espírito" ${ }^{4}{ }^{4}$

Parece-nos que esse "assombrado vaivém das ondas", aludido por Lobo Antunes em "Receita para me lerem", reflete, especularmente, a prosódia do texto de ficçção e as temáticas presentes nos romances do autor. Parece-nos possível relacionar essa expressão, que nos seduz e nos deixa estupefatos, a algumas reflexões críticas de Gilles Deleuze, inseridas em "Literatura e Vida" (Crítica e Clínica) e Cinema II imagem e tempo, entre outras, incorporadas por nós a partir da leitura de teóricos que pensam a contemporaneidade. São elas: a) "a escrita em devir, sempre inacabada e em vias de fazer-se"; b) "o surgimento de mundos de virtualidades, planos de imanência, nos quais a vida se encontra em sua máxima potência"; c) a ruptura em relação ao bom-senso e ao sensocomum, à doxa, à moral vigente, às certezas e verdades estabelecidas; d) a presença de uma nova ética e de uma nova maneira estética de se pensar o tempo e de se relacionar com o real; e) o movimento de desterritorialização e de linhas de fuga, inerentes à vida errante; f) o domínio do sensível em detrimento da representação, capaz de restabelecer o vínculo do homem com o mundo; g) as instâncias femininas de enunciação -

${ }^{42}$ ANTUNES, 2002. p. 109-111. 
"figuras" preferenciais "de uma história e de uma geografia incessantemente reinventadas" - passíveis de desnudarem o outro que existe em si próprias; $h$ ) a criação de estratégias de subjetividade e novos modos de existência - maneiras de resistir ao intolerável confinamento do presente.

Resta, portanto, aos leitores da ficção de Lobo Antunes seguir a "receita" ofertada em chave de leitura:

Caminhem pelas minhas páginas como num sonho porque é nesse sonho, nas suas claridades e nas suas sombras, que se irão achando os significados do romance, numa intensidade que corresponderá aos vossos instintos de claridade e às sombras da vossa pré-história. E, uma vez acabada a viagem e fechado o livro

convalesça. Exijo que o leitor tenha uma voz entre as vozes do romance

ou poema, ou visão, ou outro nome que lhes apeteça dar a fim de poder ter assento no meio dos demônios e dos anjos da terra. ${ }^{43}$

E caberá a esses mesmos leitores, especularmente refletidos na ficção, perguntar a si mesmos se algum dia poderão ocupar algum desses assentos, após a leitura dos romances de Lobo Antunes. Blanchot, lido por Deleuze, ao referir-se ao Livro $V$ de Spinoza, nos ensina que

Se os [quatro primeiros] livros têm por correlato 'a ausência de livro' (ou um livro mais secreto feito de carne e de sangue), o Livro $V$ pode ser essa ausência ou esse segredo em que os signos e os conceitos desfalecem e as coisas se põem a escrever por si mesmas e para si mesmas, transpondo intervalos de espaço. ${ }^{44}$

\footnotetext{
${ }^{43}$ ANTUNES, 2002, p. 109-111.

${ }^{44}$ BLANCHOT apud DELEUZE, 2011, p. 191.
} 
Assim, ao ler a ficção de Lobo Antunes, imersos, em "uma zona de indeterminação e de indiscernibilidade tal que as palavras não se distinguem umas das outras e as personagens tampouco", talvez nos sintamos, também, "figuras de uma história e de uma geografia incessantemente reinventadas".

\section{Referências}

AFONSO, Maria Fernanda. Verbete "Mar, Rios e Águas". SEIXO, M. A. (Dir.). Dicionário da obra de António Lobo Antunes. Lisboa: Imprensa Nacional-Casa da Moeda, 2008. p.357-360.

ANTUNES, António Lobo. Receita para me lerem. Segundo livro de crônicas. Lisboa: Publicações Dom Quixote, 2002. p.109-111.

ANTUNES, António Lobo. Comissão das Lágrimas. Romance. Lisboa: Publicações Dom Quixote, 2011.

ANTUNES, António Lobo. Entrevista à SIC, por ocasião da publicação do romance, 2011.

CHAUÍ, Marilena. Público, privado, despotismo. In: NOVAES, A. (Org.). Ética. $2^{\mathrm{a}}$ reimp. São Paulo: Companhia das Letras: Secretaria Municipal de Cultura, 1992. p.345-390.

DELEUZE, Gilles. Crítica e clínica. Trad. Peter Pál Pelbart. 2. ed. São Paulo: Editora 34, 2011.

DELEUZE, Gilles. A imagem-tempo. São Paulo: Brasilense, 1990.

DIAS, Ângela Maria; GLENADEL, Paula (Org.). Estéticas da crueldade. Rio de Janeiro: Atlântica Editora, 2004.

LABANYI, Jo. O reconhecimento dos fantasmas do passado: história, ética, representação. In: RIBEIRO, Margarida Calafate; FERREIRA, Ana Paula (Org.). Fantasmas e fantasias imperiais no imaginário português contemporâneo. Porto: Campo das Letras Editores, 2003. p. 59-68. 
LEVY, Tatiana Salem. A experiência do fora: Blanchot, Foucault e Deleuze. Rio de Janeiro: Civilização Brasileira, 2011.

NOVAES, Adauto. Cenários. In: NOVAES, A. (Org.). Ética. São Paulo: Companhia das Letras: Secretaria Municipal de Cultura, 1992. p. 7-15.

PEIXOTO, Nelson Brissac. Ver o invisível: a ética das imagens. In: NOVAES, A. (Org.). Ética. São Paulo: Companhia das Letras: Secretaria Municipal de Cultura, 1992. p. 301-320.

PINHEIRO, Paulo Sérgio. Estado e Terror. In: NOVAES, A. (Org.). Ética. São Paulo: Companhia das Letras: Secretaria Municipal de Cultura, 1992. p.191-204.

REAL, Miguel. Jornal de Letras, Artes e Idéias de Lisboa. Ano , n. 1069, 21 set. 2011.

RIBEIRO, Margarida Calafate; FERREIRA, Ana Paula (Org.). Fantasmas e fantasias imperiais no imaginário português contemporâneo. Porto: Campo das Letras Editores, 2003.

SEIXO, Maria Alzira. As flores do inferno e os jardins suspensos. V. II de Os romances de António Lobo Antunes. Lisboa: Publicações Dom Quixote, 2010.

\section{Resumo}

A leitura de Comissão das Lágrimas (2011), de António Lobo Antunes e de uma entrevista concedida à SIC, pelo autor, por ocasião da publicação do romance, aliada a algumas reflexões críticas de Gilles Delleuze, Maria Alzira Seixo, Jô Babanyi, Marilena Chauí, Nelson Brissac Peixoto e outros, permite-nos tecer, neste ensaio, algumas conjecturas, tais como: Qual teria sido o objetivo de Lobo Antunes, ao reencenar resíduos ou fragmentos de um determinado fato histórico questionável, ocorrido em Angola, no período da pós-independência de Portugal?; De que maneira a ficção 
referida revela uma estratégia contemporânea de desrealização narcísica, ao sucumbir a um poder mágico de simulação e de projeção de imagens, retidas na memória de determinadas personagens?; Por que podemos afirmar que há um canto fantasmático a vencer a morte, assinalado por "jardins suspensos", em meio a "flores do Inferno"? De que maneira o leitor, ao sentir-se refletido especularmente na ficção, não se descobrirá, também, uma "figura de uma história e de uma geografia incessantemente reinventadas"?

\section{Résumé}

La lecture de Comissão das Lágrimas (2011), d'António Lobo Antunes et d'une entrevue donnée à SIC, par l'auteur, à cause de la publication du roman, alliée à quelques réflexions critiques de Gilles Deleuze, Maria Alzira Seixo, Jô Babanyi, Marilena Chauí, Nelson Brissac Peixoto et d'autres, nous permet de tisser, en cet essai, quelques conjectures, comme: Quelle aurait été l'objectif de Lobo Antunes, à rejouer des résidus ou des fragments d'un fait historique discutable et particulier qui a eu lieu en Angola dans la période de postindépendance du Portugal?; De quelle manière la fiction référée révèle une stratégie contemporaine de dé-réalisation narcissique de succomber sous le pouvoir magique de simulation et de projection des images, retenues dans la mémoire des déterminés personnages?; Pourquoi ne pouvons-nous dire qu'il y a un chant fantomatique de vaincre la mort, marqué par "jardins suspendus", parmi "fleurs de l'Enfer"? De quelle manière le lecteur, à se sentir réfléchi de façon spéculaire dans la fiction, ne se découvrira pas aussi une"figure d'une histoire et $d^{\prime}$ une géographie réinventée constamment"? 
